\title{
Analysis of Success Factors to Implement Sustainable Supply Chain Management Using Interpretive Structural Modeling Technique: A Real Case Perspective
}

\author{
Mengke Yang, ${ }^{1}$ Mahmood Movahedipour,,3 Jianqiu Zeng, \\ Zhou Xiaoguang, ${ }^{1}$ and Ludi Wang ${ }^{1}$ \\ ${ }^{1}$ School of Automation, Beijing University of Posts and Telecommunications, Beijing 100876, China \\ ${ }^{2}$ School of Economic and Management, Beijing University Posts and Telecommunications, Beijing 100876, China \\ ${ }^{3}$ Academic Center for Education, Culture and Research (ACECR), Tehran 14155-4364, Iran \\ Correspondence should be addressed to Mahmood Movahedipour; mahmood.movahedipour@yahoo.com
}

Received 11 May 2017; Revised 12 July 2017; Accepted 29 August 2017; Published 10 December 2017

Academic Editor: M. L. R. Varela

Copyright (c) 2017 Mengke Yang et al. This is an open access article distributed under the Creative Commons Attribution License, which permits unrestricted use, distribution, and reproduction in any medium, provided the original work is properly cited.

Sustainability draws increased supply chain management (SCM) attention. This article analyzes critical success to the assessment, evaluation, and attainment of sustainable supply chain management (SSCM), assessed through critical-success identification and qualitative data analysis. Namely, a literature review selected of 188 articles, published between January 1994 and November 2016, helps identify the most influential success factors. The qualitative data analysis pertains to fifteen such successes, identified in the literature review and through our collaboration with other academic researchers and industrial specialists. Notably, the study's qualitative data analysis, interpretive structural modeling (ISM), unconceals the mutual impact among the most prominent SSCM success factors. The economic benefits and environmental awareness of suppliers are recognized as the most significant success factors, which could allow business enterprises and other organizations to implement a SSCM framework, with intentionality and the sustainability in their business. The article concludes with suggestions for future research directions.

\section{Introduction}

Nowadays, with people's higher and higher consideration about environmental protection, many companies have shifted their focus to SCM to achieve a sustainable competitive gain $[1,2]$. Supply managing in a sustainable behavior becomes an increasing awareness for organizations in different sizes and wide scope of industries [3].

There are a number of serious, social, economic, and environmental issues that are highly interconnected which need higher attention from industrial executives $[4,5]$. Besides, human population is also rising exponentially and it seems that there may be an increase in the natural resources consumption by nearly $170 \%$ of the earth's capacity by 2020 [6]. Also from the perspective of a developing and emerging nation, one of the major problems is the high level of carbon emissions $\left(\mathrm{CO}_{2}\right)$. It is an interesting fact that more than
$20 \%$ of global greenhouse gases emissions are made by about 2500 largest global companies, and their supply chains take the main responsibility for emissions resulting from corporate operations [7]. Moreover, developing nations generally lack an implementation of technologies that promote lower pollution as well as measures to cut down emission resulting from industrial activities [8]. Concerning social and environmental impacts, along with all stages, easier reactive approach can seem to have more responsibility for external pressure from nongovernmental organizations, consumers, and governments [9]. This study was conducted in electrical power supply manufacturing that is located in the northern part of Iran.

However, one of the most critical issues for industries of different types in recent global market is the increasing requirement for integrating eco-friendly practices into sustainable supply chain $[10,11]$. But the main point is to 
familiarize the concept of knowledge on the management point of view and make participations in the industries' sustainable supply chain network more cost effective, environmentally friendly, and socially practical [12]. For this order, it calls for the need to identify different types of success to implement SSCM and to extend a hierarchy of ISM to apply SSCM to sustainable practices.

Purposes and Forms of This Study. This study has some purposes, shown as follows:

(i) To undertake a systematic literature review to distinguish key critical success factors in SSCM practices to implement SSCM towards sustainable practices from industrial point of view

(ii) To identify the mutual relationships between identified success factors of SSCM practices by ISM and MICMAC analysis

(iii) To confer the research managerial implications.

The rest of the research is arranged as follows: in the second chapter we outline our systematic literature review. In the third part we show the theoretical framework for the solution method of this research. Section 4 presents the outline of our SSCM theoretical framework as the outcome of the MICMAC analysis. Then we relate this to literature in the discussion, Section 5, and in Section 6, we conclude our research and provide suggestions for further research directions.

\section{Literature Review}

2.1. Initial Data Statistics. The concepts of supply chain management and environmental management as strategic organizational practices to gain competitive advantage have been receiving increased attention especially during the period of the late 1980s and early 1990s [13]. Identifying the appropriate search terms and keyword structure was completed through several trial and error attempts.

We used the following iterative multistep process to design an effective keyword structure:

(i) Defining initial set of keywords and search structure

(ii) Checking the resulting articles and journals to ensure the appropriate coverage (whether key articles and major journals are appearing in search results) and updating the keywords accordingly

(iii) Looking for irrelevant articles and research areas, identifying the "exclusion keywords," and updating the keyword structure accordingly

(iv) Looking for irrelevant subject areas to narrow down the search space and updating the keyword structure accordingly.

The following subject areas were found to be irrelevant to our review scope: (1) sustainable, (2) sustainability environmental, (3) sustainability environmentally, sustainable environmentally, (4) sustainable supply chain managements, (5) green, (6) green supply chain management, (7) ecological sustainable, (8) ecological economics, (9) gas emission, (10)

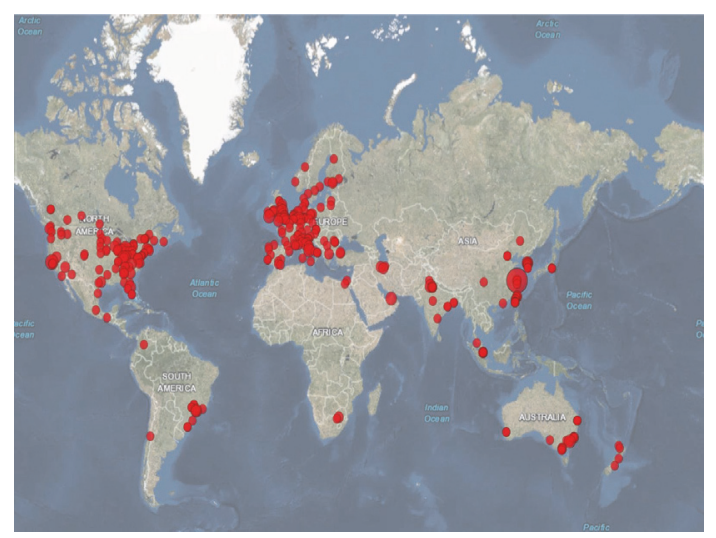

FIGURE 1: Geographical locations of all contributing organizations.

environmental resources management, and (11) sustainable development. This reduced the number of relevant articles to 1,780 . The search results were stored in RIS4 format to include all the essential article information such as article title, authors' names and affiliations, abstract, keywords, and references.

2.2. Refinement of the Search Results. BibExcel allows modifying and/or adjusting the data imported from various databases including Scopus and Web of Science. The data output can be exported to Excel or any program that takes tabbed data records. This high degree of flexibility makes BibExcel a powerful tool, yet relatively difficult to work with especially in performing the initial setups. We use BibExcel to perform some initial bibliometric and statistical analysis and to prepare the input data for additional network analysis in Gephi. The data source that we use as input into BibExcel is in RIS format (Scopus output) containing the bibliographic information of the articles. Our analysis focuses on the following data fields: authors, title, journal, publication year, keywords, abstract, affiliations, and references. These analyses require reformatting of the RIS file into a number of different formats and hence producing several file types.

Now, the data transfer to Bib Excel software is possible for future process. After this stage the analyzed data conduct to Global Positioning System (GPS) visualizer web site for building multiple geocodes. For this purpose we used the "http://www.gpsvisualizer.com" web site. It is a free GPS visualizer online to make maps from geographic data. There is some limitation to draw a map for multiple geocodes but with asking keyword mapping from "Google Map" or "Bing Map" website we could create our geographical map with large numbers of cities. Figure 1 shows the map which is created by "GPS visualizer" [15] (GPS 2003-2016 Visualizer) online website. It shows the institutions' location which works on different branches of sustainable supply chain network. The large numbers of literatures are located in some western countries in Europe and then west states in USA. Also the number of publications in western Asia is impressive. In Figure 1 the diameter of each circle expresses the relative degree of each institution to the contribution. In general view, in the map, the geographical distribution of these institutions 


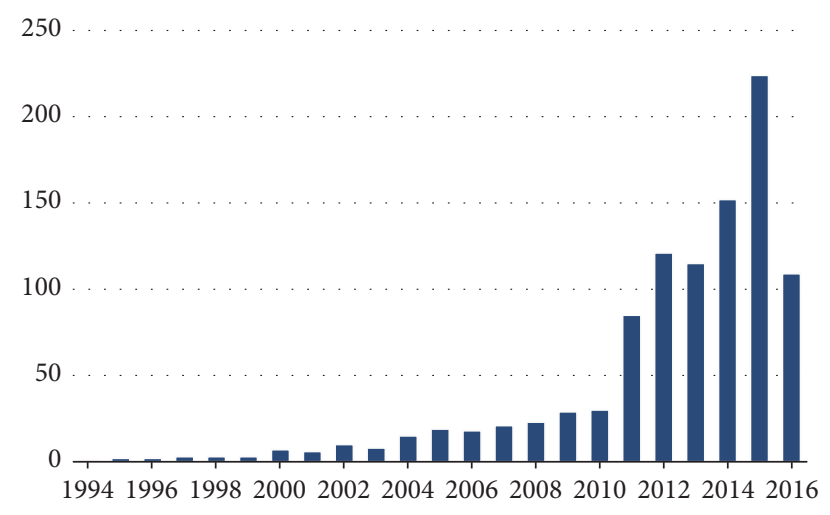

Figure 2: Publication trend in the area of SSCM.

expresses that sustainable supply chain network has attracted many researchers around the world.

Our map on the national collaborations statistics shows that the United States holds the highest national collaboration rate. There are 229 affiliations belonging to USA, followed by 70 affiliations with UK. This could be most likely encouraged by the many top authors and organizations within the United States. While still in its early growth and expansion period, the area of sustainable supply chain managements is attracting a geometric growth in the number of academic publications. This significant growth is more noticeable after 2010. The details of a number of publications are illustrated in Figure 2.

2.3. Sustainable Supply Chain and Success Factors. Sustainable supply chain concerns the management of material, information, and capital flows as well as cooperation among companies along the supply chain while taking goals from all three dimensions of sustainable development, that is, economic, environmental, and social, into account which are derived from customer and stakeholder requirements. Therefore, SSCM can be understood as SCM focusing on maintaining environmental, economic, and social stability for long-term sustainable growth. We focused on 188 articles which are more compatible with our topic. From these literatures we classified the key success of SSCM. Fifteen themes arose, as explained in the following subsections.

2.3.1. Initiation and Commitment of Top Management (S1). Top management commitment and support is a fundamental requirement for a company to manufacture environmentally friendly products, and a primary decision rests on which supplier will enhance the green supply chain of a company [16]. Initiation and commitment of top management are necessary for any organization to allocate adequate technological, financial, and human resources for adopting SSCM concepts, ideas, and strategy development. Top management commitment helps in achieving resources for effective implementation of organizational sustainable supply chain management initiatives.

2.3.2. Strategic Planning (S2). Domestic government legislations and environmental regulations are of the major drivers affecting strategic planning in SSCM practices adoption in any country $[17,18]$. Organizations need to respond to the government policies and regulations of the concerned countries towards greening the firms.

2.3.3. State Government Legalizations (S3). The authors in [19] believe that state regulatory framework plays significant importance in promotion environmental sustainability [20]. Again there are several cells, boards, and units under them to look after the issues. In state level, there are similar "bodies" for promoting green practices. State government regulation has been identified as an important success factor to implement SSCM practices.

2.3.4. Societal Issues (S4). Societal issues are product/process related aspects of operations that influence human safety, welfare, and community development [21-23]. Strong business ethics is an essential factor for the success of sustainability initiatives in an organization. Some subthemes are important in this section: rights, ethics, poverty, and increasing sustainable development to consider major contributions and promise fields to further the area. References $[24,25]$ examined briefly the conceptualizations of SSM and of social responsibility, to show the understanding of topics.

2.3.5. Encouragement from Customers (S5). Organizations should design and manufacture products by considering environment properties of products/services which must meet customers' requirements and expectations to obtain most sustainable solution [23]. The customer is the essence of any business. Businesses must design and manufacture products and provide services that meet customers' needs and expectations. Environmental consciousness of consumers is one of the most significant driving forces for companies to engage in environmental management $[26,27]$.

2.3.6. Motivation of Suppliers and Vendors towards Green Practices (S6). Perception of an organization of taking steps towards environmental good-will is not their responsibility. Lack of appropriate organizational structures and widespread ignorance of supply chain philosophy are also success factors identified for implementation of GSCM [28]. Companies could find they are not fully familiar with the real risks and costs and connected to their investments over time.

2.3.7. Economic Benefits (S7). There is a lack of funds for environmental projects or the consideration that Return on Investment (ROI) period after implementing green supply chain management is very long. Taking over GSCM initiatives needs additional endeavors and also higher cost and it has less visible economic benefits from these initiatives $[29,30]$. In this situation, the value of national money will decrease and prices will increase, which empowers hesitation between customers and investors. Reference [31] explained that weak economic performance could lead to government collapse and diplomatic unrest.

2.3.8. Scarcity of Natural Resources (S8). Industrial professionals need training to adopt SSCM system in their 
industries and need training to maintain and monitor growth [32]. The growth of gross domestic product has been raised. Effective employees' training offers several potential advantages in real life. Most social benefits, derived from the accumulation of human skills, such as good health, more urban employment, reduction of crime, and increase in social correlation, will affect the economic growth in the long term.

2.3.9. Firm's Competitiveness (S9). Organizations implementing green innovation can enjoy the first mover advantage and, at the same time, improve their corporate images, develop new markets, and gain competitive advantages [33]. Supplying must pay high attention to supply chain sustainability issues, while the environmental benefits may hold them responsible for unsustainable supply chain behaviors. Mostly, unsustainability obstacles occur upstream at the different subsupplier stages [34].

2.3.10. Information Quality and Sharing (S10). An efficient interorganizations/intraorganization communication, sharing of innovative ideas, and developing healthy organizational culture in implementing of SSC activities can be achieved through information sharing among industries [35, 36]. Sustainable technologies are cleaner and reconfigurable and even recyclable, which do not harm the nature but need high investment $[37,38]$; also waste treatment is another important area that needs attention in the sustainable development strategy. Thus, we argue that enabling advanced technologies and information should be taken into consideration as an enabler in the strategic framework formulation of sustainable supply chain.

2.3.11. State Government Legalizations (S11). There is a lack of number of laborers in the organization and/or the quality of the employees. Basically, a fundamental obstacle to improving environmental performance of the SME sector is a lack of state government legalizations [39]. But among the item mentioned above, the task of developing human resources in both developed and developing industries is accepted as a vital need in the societies [40].

2.3.12. Fearlessness of Failure (S12). The fear of failure is involved while adopting sustainable supply chain which could lead to monetary losses for the firm or the fear of failure of the product, hence leading to losing the competitive advantage [41]. Sustainable development approach reflects on the role of information as a strategic resource in supply chain [42]. Reference [43] further emphasized the need to develop reverse logistics networks, to increase the utilization of resources and for the reuse and recycling of the product.

2.3.13. Pressure from Non-Government Organizations (NGOs) Lobby (S13). Legislation and regulation are the instruments very much necessary for the proper governance of business enterprises including the environment in which they operate. Environmental laws and regulations are an important framework, within which the companies must operate [44]. In the large scale, environmental pollution caused by factory production processes in the other side costs of production conducts to be lower than related community costs [45]. Due to high attention to the environmental protection and sustainable development, such as pressures from NGOs and stakeholder groups, organizations are being pushed to effectively incorporate sustainability issues into their supply chain network managing program [46].

2.3.14. Measure and Monitor the Environmental Practice of Suppliers (S14). Metrics misalignment is thought to be a primary source of inefficiency and disruption in supply chain interactions [47]. It means sustainability practice or environmental protection is one of the goals that exist in organization. The good summary of the aims with a sustainability keeps focusing the organizations on track during adverse times and leads to fighting the inner battle among commercialization and esteemed values.

2.3.15. Maintaining the Environmental Awareness of Suppliers (S15). Industries are unable to maintain the environmental conscious suppliers and suppliers also are concerned to maintain the environmental concepts in their industries [48]. The growing recognition of the contribution of local areas to energy and environmental policies has led to important initiatives for the reallocation of planning actions [49].

\section{Research Gap}

Adopting sustainable concepts in traditional supply chain management is very difficult, and there are many obstacles to integrating environmental consciousness in traditional SCM. Based on our systematic literature, it is found that in this field many researchers worked on performance and enablers for the adopting of SSCM in different branches [50-52] and that only a handful of researchers address the analysis among the critical success for implementation of SSCM in organizations $[14,53]$. One serious issue in industries is environmental contamination. The manufacturing industries have started to adopt sustainable concepts in their SCM in order to retain their customers. This study is helpful for industries to analyze the success for SSCM and to find the key success; industries will also be able to improve their sustainable performance by identifying the leading or dominant success for adopting sustainable supply chain management. It is difficult for industries to eradicate all the success in the initial stage of adopting sustainable concepts in traditional SCM.

\section{Solution Methodology}

4.1. Interpretive Structural Modeling. The ISM is a qualitative data analysis which was proposed by [54]. Firstly it was used as a solving method to basically understand and identify the interrelationships of the components in sophisticated systems or condition [55]. Also ISM is based on group decisionmaking, social sciences, discrete mathematics, graph theory, and computer assistance [56]. The ISM methodology is started by separately or group mental types in order to calculate binary matrices, to explain the individual/mutual relations of the elements. In some references this matrix is nominated as relation matrix too [38]. 
The relation matrix may be shaped by considering this question "regarding this feature will $e_{i}$ effect $e_{j}$ ?" Following the reply, if it is "no" then $\pi_{i j}=0$; otherwise $\pi_{i j}=1$. The relation matrix, in general form, is shown as follows:

$$
D=\begin{gathered}
e_{1} \\
e_{2} \\
\vdots \\
e_{m}
\end{gathered}\left(\begin{array}{cccc}
0 & \pi_{12} & \cdots & \pi_{1 n} \\
\pi_{21} & 0 & \cdots & \pi_{2 n} \\
\vdots & \vdots & \ddots & \vdots \\
\pi_{m 1} & \pi_{m 2} & \cdots & 0
\end{array}\right) .
$$

Here " $e_{i}$ " is the same as " $i$ th" variable in the framework. " $\pi_{i j}$ " also reveals the connection among "ith" and " $j$ th" variables. $D$ is the relation matrix.

$$
\begin{aligned}
M & =D+I, \\
M^{*} & =M^{K}=M^{K+1}, \quad K \geq 0 .
\end{aligned}
$$

In (2), " $I$ " is nominated as the unit matrix, and in (3) " $K$ " express the powers. Also in (3) $M^{*}$ presented the reachability matrix. Keep in mind that this matrix runs under the "Boolean operation" (e.g., $1 \times 1=1$ and $0 \times 0=0$; see as follows)

$$
\begin{aligned}
M & =\left(\begin{array}{ll}
1 & 0 \\
1 & 1
\end{array}\right), \\
M^{2} & =\left(\begin{array}{ll}
1 & 0 \\
1 & 1
\end{array}\right) .
\end{aligned}
$$

Now, we are ready to calculate the reachability matrix and priority matrix, respectively, as follows:

$$
\begin{aligned}
& R\left(t_{i}\right)=\left\{e_{i} \mid m^{*}{ }_{j i}=1\right\}, \\
& A\left(t_{i}\right)=\left\{e_{i} \mid m^{*}{ }_{i j}=1\right\} .
\end{aligned}
$$

" $m_{i j}$ " explains the value of the "ith" and " $j$ th" in row and column, respectively.

Now, based on (7), the interrelationships among the elements could be discovered and the arrangement of the relationship of elements could be explained by the graph

$$
R\left(t_{i}\right) \cap A\left(t_{i}\right)=R\left(t_{i}\right) .
$$

4.2. The Main ISM Steps. The various steps involved in the ISM methodology are described as follows.

Step 1. Variables (criteria) considered for the system under consideration are listed.

Step 2. From the variables identified in Step 1, a contextual relationship is established among the variables in order to identify which pairs of variables should be examined.

Step 3. A structural self-interaction matrix (SSIM) is developed for variables, which indicates pairwise relationships among variables of the system under consideration.
Step 4. Reachability matrix is developed from the SSIM and the matrix is checked for transitivity. The transitivity of the contextual relation is a basic assumption made in ISM. It states that if a variable $A$ is related to $B$ and $B$ is related to $C$, then $A$ is necessarily related to $C$.

Step 5. The reachability matrix obtained in Step 4 is partitioned into different levels.

Step 6. Based on the relationships given above in the reachability matrix, a directed graph is drawn and the transitive links are removed.

Step 7. The resultant digraph is converted into an ISM, by replacing variable nodes with statements.

Step 8. The ISM model developed in Step 7 is reviewed to check for conceptual inconsistency and necessary modifications are made. The above steps and necessary modifications are made [18] which are indicated in Figure 3.

4.3. Interpretive Structural Modeling. The ISM technique is a well-known methodology for identifying and summarizing relationships between specific elements. In the first step to develop the theoretical framework, we use ISM to recognize the mentioned fifteen successes of SSM based on our systematic literature review in the previous sections. This methodology allows an interactive learning practice and helps to understand the complex relationships among variables of systems. To find experts we identified practitioners who have implemented sustainability initiatives within their supply chains. They have suitable experience and are working at tactical operation in different levels of supply chain. The experts were consulted to verify the drivers that were stemmed from the literature review in the context of manufacturing. The wording of the variables was verified but we did not drop or add new variables.

4.4. Sampling Design and Data Collection. In our study, 12 manufacturing firms were identified from various sectors including electrical power supply, UPSs and battery charger consumer goods, and batteries. The targeted experts have twenty plus years of experience and were working in the tactic level of supply chain operations. Ten academics from reputable engineering and management institutes were also consulted for the survey of the SSCM drivers. The use of professional networking sites made our efforts much easier. The questionnaire was emailed to a total of 24 experts out of which 32 exploitable responses were considered for the study. Thus, we achieved a response rate of $75 \%$. The flow chart or our research is illustrated in Figure 4.

4.5. Structural Interpretive Matrix. As per ISM technique, we used the survey to establish the contextual relationships between the drivers identified earlier, and the structural selfinteraction matrix (SSIM) emerged [14, 57]. The relationship among the variables in the survey is denoted by $V, A, X$, 


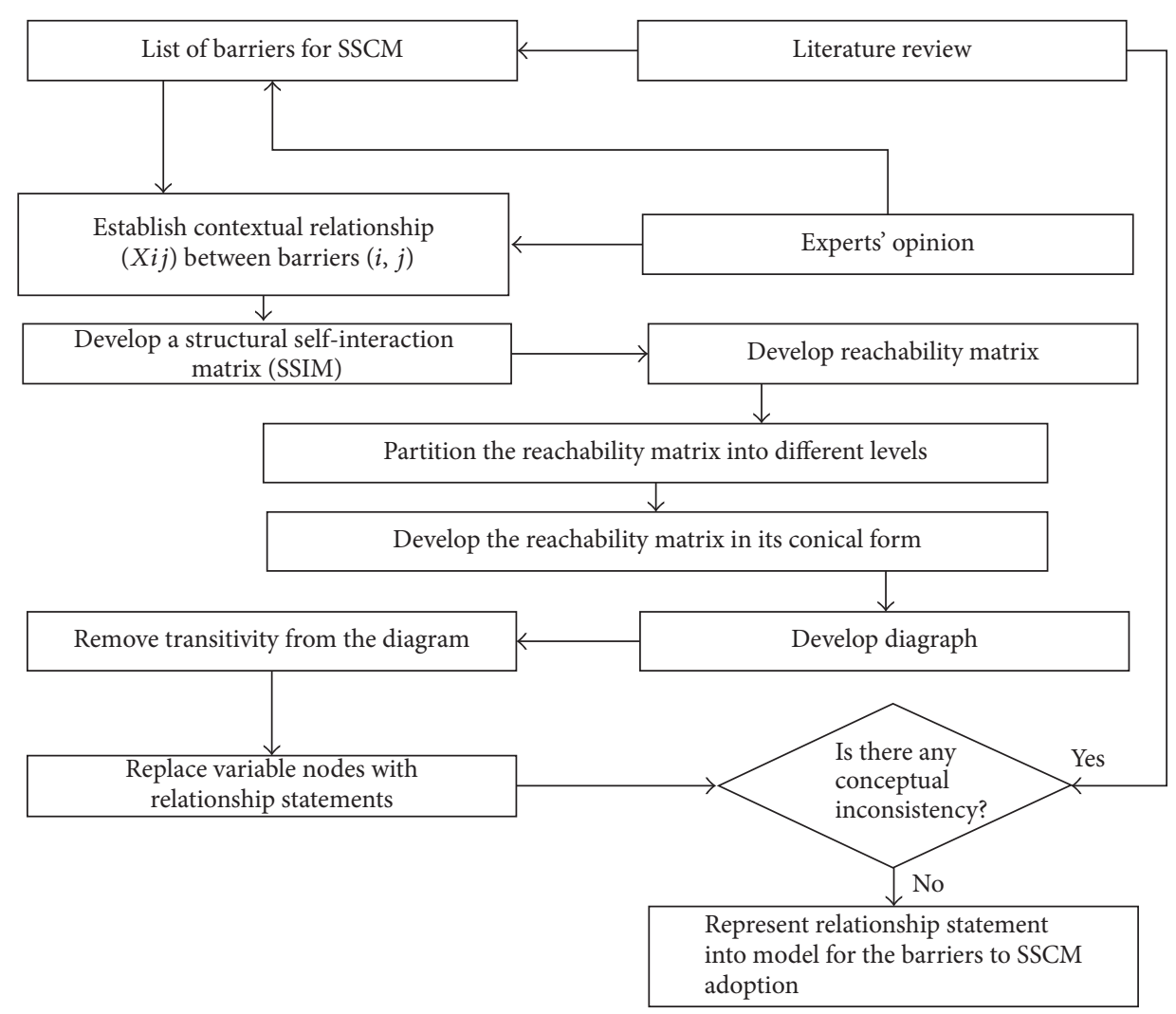

FIGURE 3: ISM diagram modified from [14].

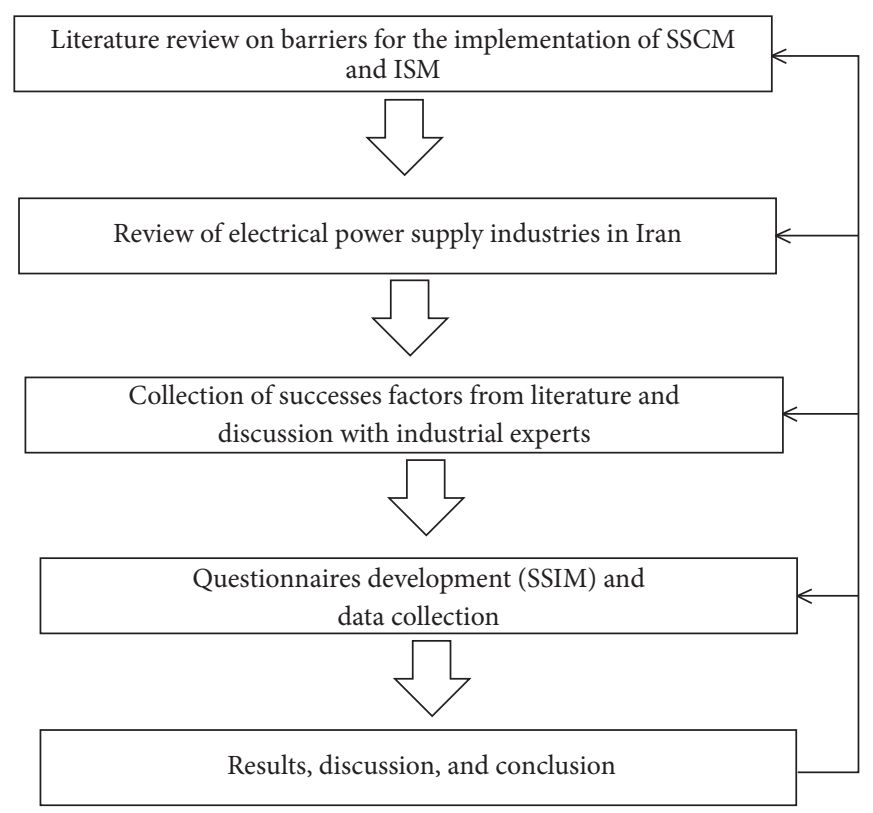

FIGURE 4: Flow chart of the research work.

and $O$. Using the symbols $i$ and $j$ to denote columns and rows, the relationships between nodes are shown as follows:

$V$ : if $i$ leads to $j$ but $j$ does not lead to $i$

$A$ : if $i$ does not lead to $j$ but $j$ leads to $i$

$X:$ if $i$ and $j$ lead to each other
$O$ : if $i$ and $j$ are not related each other.

In Table 1, structural self-interaction matrix is shown.

4.6. Structural Model. The SSIM (Table 1) is further converted into initial and final reachability matrices (see Tables 
TABLE 1: Structural self-interaction matrix (SSIM).

\begin{tabular}{|c|c|c|c|c|c|c|c|c|c|c|c|c|c|c|}
\hline Success factor & $\mathrm{S} 15$ & S14 & S13 & $\mathrm{S} 12$ & S11 & $\mathrm{S} 10$ & S9 & S8 & S7 & S6 & S5 & S4 & S3 & S2 \\
\hline S1 & $X$ & $V$ & V & $A$ & $A$ & $X$ & $V$ & $A$ & $A$ & $A$ & $A$ & $V$ & $A$ & $A$ \\
\hline S2 & $A$ & $A$ & $\mathrm{O}$ & $O$ & $X$ & $\mathrm{O}$ & $O$ & $A$ & $A$ & $V$ & $X$ & $V$ & $X$ & \\
\hline S3 & $\mathrm{O}$ & $A$ & $\mathrm{O}$ & $X$ & $A$ & $A$ & $A$ & $A$ & $X$ & $O$ & $X$ & $A$ & & \\
\hline S4 & $O$ & $X$ & V & V & $X$ & $V$ & $O$ & $V$ & $V$ & $X$ & $V$ & & & \\
\hline S5 & $A$ & $A$ & $\mathrm{O}$ & $V$ & $X$ & $A$ & $A$ & $A$ & $A$ & $O$ & & & & \\
\hline S6 & $X$ & $X$ & $\mathrm{O}$ & $O$ & $O$ & $\mathrm{O}$ & $O$ & $O$ & $V$ & & & & & \\
\hline S7 & $X$ & $A$ & $\mathrm{O}$ & $\mathrm{O}$ & V & $A$ & $O$ & $X$ & & & & & & \\
\hline S8 & $V$ & $O$ & V & V & V & $A$ & $A$ & & & & & & & \\
\hline S9 & $O$ & $A$ & $X$ & V & $O$ & $X$ & & & & & & & & \\
\hline $\mathrm{S} 10$ & V & V & V & $V$ & $V$ & & & & & & & & & \\
\hline S11 & $A$ & $A$ & $O$ & $O$ & & & & & & & & & & \\
\hline $\mathrm{S} 12$ & $O$ & $A$ & $X$ & & & & & & & & & & & \\
\hline $\mathrm{S} 13$ & $A$ & $V$ & & & & & & & & & & & & \\
\hline S14 & O & & & & & & & & & & & & & \\
\hline
\end{tabular}

TABLE 2: Initial reachability matrix.

\begin{tabular}{|c|c|c|c|c|c|c|c|c|c|c|c|c|c|c|c|}
\hline Success factor & $\mathrm{S} 1$ & S2 & S3 & $\mathrm{S} 4$ & S5 & S6 & S7 & S8 & S9 & $\mathrm{S} 10$ & S11 & $\mathrm{S} 12$ & $\mathrm{~S} 13$ & S14 & S15 \\
\hline $\mathrm{S} 1$ & 0 & 0 & 0 & 0 & 0 & 0 & 0 & 0 & 0 & 0 & 0 & 0 & 0 & 0 & 0 \\
\hline S2 & 0 & 0 & 0 & 0 & 0 & 0 & 0 & 0 & 0 & 0 & 0 & 0 & 0 & 0 & 0 \\
\hline S3 & 0 & 0 & 0 & 0 & 1 & 0 & 0 & 0 & 0 & 0 & 0 & 0 & 0 & 0 & 1 \\
\hline S4 & 1 & 1 & 1 & 0 & 1 & 0 & 1 & 1 & 0 & 0 & 1 & 1 & 1 & 0 & 0 \\
\hline S5 & 1 & 1 & 1 & 0 & 1 & 0 & 0 & 0 & 0 & 0 & 1 & 1 & 1 & 0 & 0 \\
\hline S6 & 0 & 0 & 0 & 0 & 0 & 1 & 0 & 0 & 0 & 0 & 0 & 0 & 0 & 0 & 0 \\
\hline S7 & 0 & 0 & 0 & 0 & 1 & 0 & 0 & 0 & 0 & 0 & 0 & 0 & 0 & 0 & 1 \\
\hline S8 & 1 & 1 & 1 & 0 & 1 & 0 & 1 & 1 & 0 & 0 & 1 & 1 & 1 & 0 & 0 \\
\hline S9 & 1 & 1 & 1 & 0 & 1 & 0 & 0 & 0 & 0 & 0 & 1 & 1 & 1 & 0 & 0 \\
\hline $\mathrm{S} 10$ & 0 & 0 & 0 & 0 & 0 & 1 & 0 & 0 & 0 & 0 & 0 & 0 & 0 & 0 & 0 \\
\hline S11 & 1 & 0 & 0 & 0 & 1 & 0 & 1 & 0 & 0 & 0 & 1 & 0 & 0 & 0 & 0 \\
\hline $\mathrm{S} 12$ & 1 & 1 & 1 & 0 & 1 & 0 & 1 & 1 & 1 & 0 & 1 & 1 & 1 & 0 & 1 \\
\hline $\mathrm{S} 13$ & 1 & 1 & 1 & 0 & 1 & 0 & 0 & 0 & 1 & 0 & 1 & 1 & 1 & 0 & 1 \\
\hline S14 & 0 & 0 & 0 & 0 & 1 & 0 & 0 & 0 & 0 & 0 & 0 & 0 & 0 & 0 & 1 \\
\hline S15 & 1 & 1 & 1 & 0 & 1 & $\mathbf{0}$ & 1 & 1 & $\mathbf{0}$ & 0 & 1 & 1 & 1 & $\mathbf{0}$ & 0 \\
\hline
\end{tabular}

2 and 3). The initial reachability matrix emerged when we converted the SSIM by substituting $V, A, X$, and $O$ by 1 and 0 ; as per the following rules SSIM becomes binary format, for example, 0 or 1 ; the instruction for substitution is mentioned as follows based on [58].

(i) If the $(i, j)$ relationship in SSIM is $V$, the corresponding binary relationship is 1 for $(i, j)$ and is 0 for $(j, i)$.

(ii) If the $(i, j)$ relationship in SSIM is $A$, the corresponding binary relationship is 0 for $(i, j)$ and is 1 for $(j, i)$.

(iii) If the $(i, j)$ relationship in SSIM is $X$, the corresponding binary relationship is 1 for both $(j, i)$ and $(i, j)$.

(iv) If the $(i, j)$ relationship in SSIM is $O$, the corresponding binary relationship is 0 for both $(j, i)$ and $(i, j)$.

As the above rules, the initial reachability matrix is shown in Table 2.
4.7. Structural Final Reachability Matrix. The transitivity principle can be explained with an illustrative example: if $a$ leads to $b$ and $b$ leads to $c$, the transitivity property implies that $a$ leads to $c$. The transitivity property helps to remove the gaps among the variables if any. By adopting the above criteria, the final reachability matrix is prepared and is shown in Table 3 based on [14].

4.8. Level Partitioning. The fifth step involves extracting of a hierarchical ordering from the reachability matrix by level partitioning [59]. The reason for this step is to make easy construction of the digraph from the reachability matrix. From the final reachability matrix, the reachability and antecedent sets for each success factor are established. The level partition related to this research is shown in Table 4.

4.9. ISM Model. Based on final reachability matrix, the structural model is introduced as follows. 
TABLE 3: Final reachability matrix.

\begin{tabular}{lccccccccccccccc}
\hline Success factor & S1 & S2 & S3 & S4 & S5 & S6 & S7 & S8 & S9 & S10 & S11 & S12 & S13 & S14 & S15 \\
\hline S1 & 0 & 0 & 0 & 0 & 0 & 0 & 0 & 0 & 0 & 0 & 0 & 0 & 0 & 0 & 0 \\
B2 & 0 & 0 & 0 & 0 & 0 & 0 & 0 & 0 & 0 & 0 & 0 & 0 & 0 & 0 & 0 \\
S3 & $1^{*}$ & $1^{*}$ & 0 & 0 & $1^{*}$ & $1^{*}$ & $1^{*}$ & $1^{*}$ & 0 & 0 & $1^{*}$ & $1^{*}$ & $1^{*}$ & 0 & 1 \\
S4 & 0 & 0 & 0 & 0 & 0 & 0 & 0 & 0 & 0 & 0 & 0 & 0 & 0 & 0 & 0 \\
S5 & 0 & 0 & 0 & 0 & 0 & 0 & 0 & 0 & 0 & 0 & 0 & 0 & 0 & 0 & 0 \\
S6 & $1^{*}$ & $1^{*}$ & 0 & 0 & $1^{*}$ & $1^{*}$ & $1^{*}$ & $1^{*}$ & 0 & 0 & $1^{*}$ & $1^{*}$ & $1^{*}$ & 0 & 1 \\
S7 & 1 & 1 & $1^{*}$ & 0 & 1 & 1 & 1 & 1 & $1^{*}$ & 0 & 1 & 1 & 1 & 0 & $1^{*}$ \\
S8 & 1 & 1 & 0 & 0 & 1 & 1 & 1 & 1 & 0 & 0 & 1 & 1 & 1 & 0 & $1^{*}$ \\
S9 & 0 & 0 & 0 & 0 & 0 & 0 & 0 & 0 & 0 & 0 & 0 & 0 & 0 & 0 & 0 \\
S10 & $1^{*}$ & $1^{*}$ & 0 & 0 & $1^{*}$ & $1^{*}$ & $1^{*}$ & $1^{*}$ & 0 & 0 & $1^{*}$ & $1^{*}$ & $1^{*}$ & 0 & 1 \\
S11 & 1 & 1 & $1^{*}$ & 0 & 1 & 1 & 1 & 1 & $1^{*}$ & 0 & 1 & 1 & 1 & 0 & $1^{*}$ \\
S12 & 1 & 1 & 0 & 0 & 1 & 1 & 1 & 1 & 0 & 0 & 1 & 1 & 1 & 0 & $1^{*}$ \\
S13 & 0 & 0 & 0 & 0 & 0 & 0 & 0 & 0 & 0 & 0 & 0 & 0 & 0 & 0 & 0 \\
S14 & 0 & $1^{*}$ & 0 & 0 & 1 & 0 & 0 & $1^{*}$ & 0 & 0 & 1 & 0 & $1^{*}$ & 0 & $1^{*}$ \\
S15 & $\mathbf{0}$ & $\mathbf{0}$ & $\mathbf{0}$ & $\mathbf{0}$ & $\mathbf{0}$ & $\mathbf{0}$ & $\mathbf{0}$ & $\mathbf{0}$ & $\mathbf{0}$ & $\mathbf{0}$ & $\mathbf{0}$ & $\mathbf{0}$ & $\mathbf{0}$ & $\mathbf{0}$ & $\mathbf{0}$ \\
\hline
\end{tabular}

${ }^{*}$ Entries are included to incorporate transitivity.

TABLE 4: Level partition.

\begin{tabular}{lcccc}
\hline Success factor & Reachability set & Antecedent set & Intersection set & Level \\
\hline S10 & 7 & $1,2,3,4,5,6,7,8,9,10,11,14,15$ & 1 & I \\
S14 & 9 & $3,4,5,7,8,9,10,11,12,13,14,15$ & 2 \\
S13 & 8 & $2,3,4,5,7,8,9,10,11,14,15$ & 6 & II \\
S2 & 14 & $5,7,8,9,10$ & 12 & II \\
S12 & 4 & $1,2,3,4,5,6,7,8,9,10,14,15$ & $3,5,11,15$ & II \\
S3 & $4,7,8,10,14$ & $3,4,5,7,8,9,10,11,14,15$ & $3,11,15$ & III \\
S9 & $4,8,9,10,14$ & $3,4,5,7,8,9,10,11,14,15$ & $3,5,11,15$ & III \\
S8 & $4,8,10$ & $3,4,5,7,8,9,10,11,15$ & 3,15 & III \\
S4 & $4,7,8,10,14$ & $3,4,5,7,8,9,10,11,15$ & III \\
S5 & 1 & $3,5,11,15$ & 9 & IV \\
S11 & 13 & $3,5,11,15$ & IV \\
S1 & 2 & $3,5,11,15$ & IV \\
S6 & 6 & $3,5,11,15$ & V \\
S7 & 12 & $3,5,11,15$ & VI \\
S15 & 10 & $3,5,11,15$ & VI \\
\hline
\end{tabular}

If there is any interrelationship among the successes $j$ and $i$, an arrow is used to show this relationship. The output result is named as "digraph." With the replacing of nodes, the "digraph" will convert to an ISM model. In Figure 3, we illustrated ISM model structure. As this ISM model, the 15 success factors are categorized in six levels. In the top level, two successes appear, which are "information quality and sharing (S10)" in minimum level, and economic benefits (S7) and "maintaining the environmental awareness of suppliers (S15)" are found as maximum level illustrated in Figure 6.

4.10. MICMAC Analysis. Based on dependence power and driving power matrix (Table 5), it is desirable to seek a method by which we can draw up the hierarchical relationship among them and also establish which of the myriad indicators are "stand-alone" ones in their impacts, which ones do not hold true, and which ones generate secondary and higher order impacts. Cross impact matrix multiplication applied to classification (MICMAC) can be used as the best tool to meet the purpose. Based on this research, all successes are categorized into four modules: independent, autonomous, linkage, and dependent. Also it is divided into two main parts: dependence power and driver power, which are given in Figure 5:

(i) Success factors in autonomous quadrant: in this section, successes do not have strong driving power and also weak dependence. Usually they keep disconnected from the system life cycle, but in some parts they have a few connections, which could be strong. These types of success are appointed in quadrant I. 


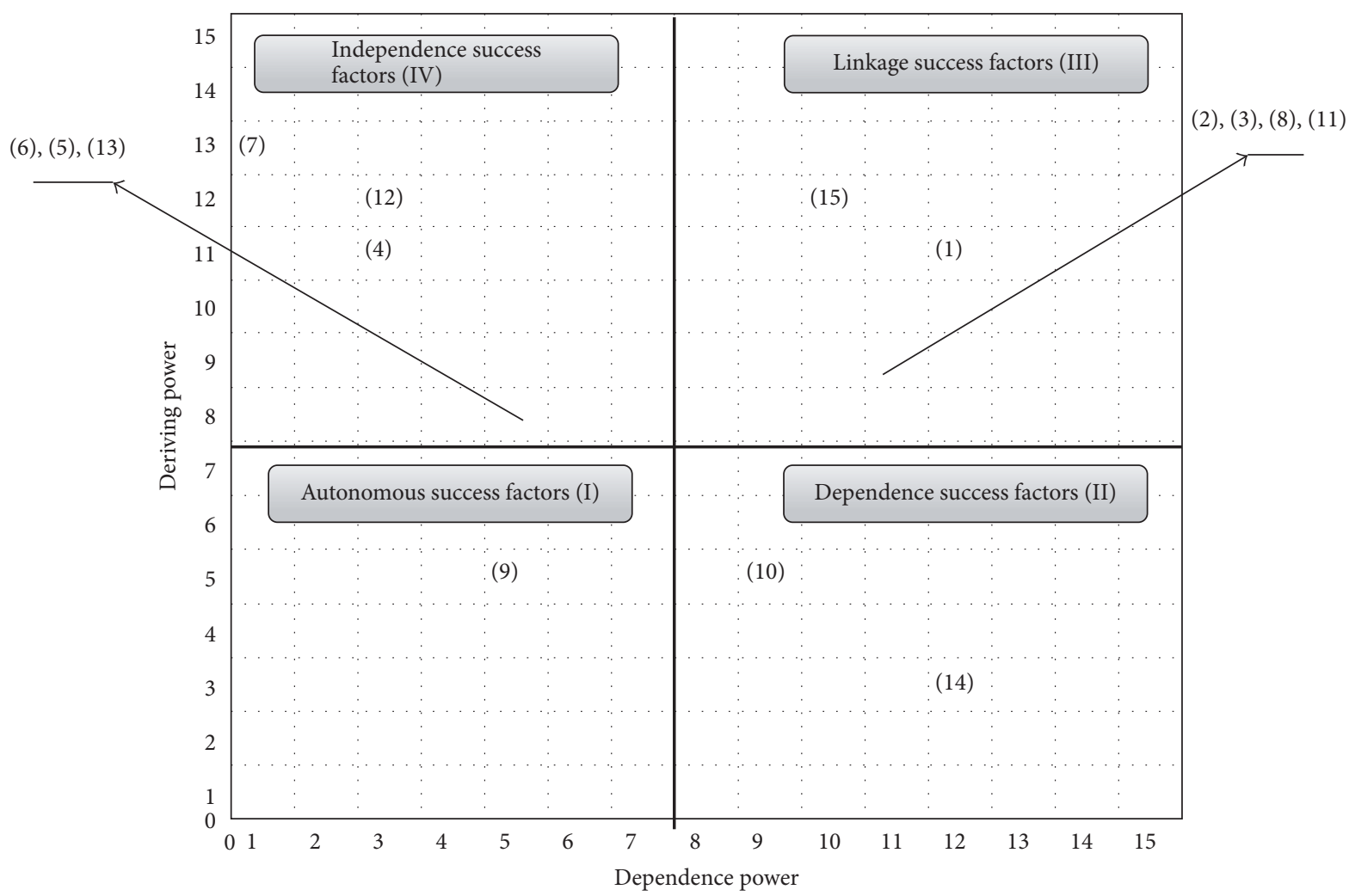

FIGURE 5: MICMAC analysis towards implementing SSM, a case industry under study.

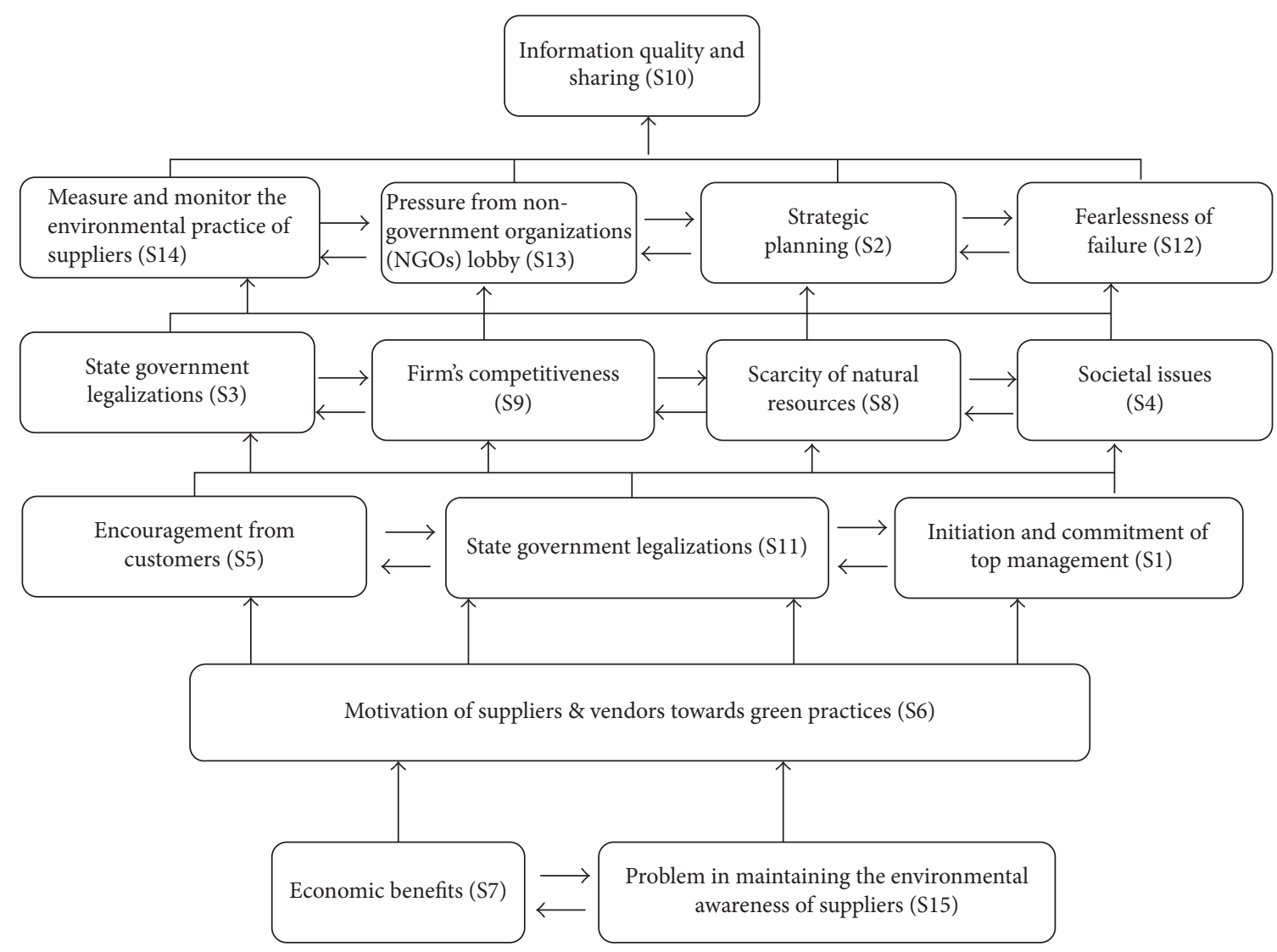

FIGURE 6: ISM based model for success factors. 
TABLE 5: Dependence power and driving power.

\begin{tabular}{lcccccccccccccccc}
\hline Success factor & S4 & S3 & S5 & S6 & S11 & S9 & S13 & S12 & S15 & S2 & S8 & S7 & S14 & S1 & S10 & Driver power \\
\hline S1 & 0 & 0 & 0 & 0 & 0 & 0 & 0 & 0 & 1 & 0 & 0 & 0 & 0 & 0 & 0 & 1 \\
S11 & 0 & 0 & 0 & 0 & 0 & 0 & 0 & 0 & 0 & 0 & 0 & 1 & 0 & 0 & 0 & 1 \\
S2 & 0 & 0 & 0 & 1 & 0 & 1 & 0 & 0 & 0 & 0 & 0 & 0 & 0 & 0 & 0 & 2 \\
S5 & 0 & 0 & 0 & 0 & 0 & 0 & 0 & 0 & 0 & 0 & 0 & 0 & 0 & 0 & 0 & 2 \\
S12 & 0 & 0 & 0 & 0 & 0 & 0 & 0 & 1 & 0 & 0 & 1 & 0 & 0 & 0 & 0 & 2 \\
S3 & 0 & 1 & 1 & 0 & 1 & 1 & 1 & 1 & 1 & 0 & 0 & 0 & 1 & 0 & 0 & 8 \\
S6 & 0 & 1 & 1 & 0 & 1 & 1 & 1 & 1 & 1 & 0 & 0 & 0 & 0 & 0 & 1 & 8 \\
S13 & 0 & 1 & 1 & 0 & 1 & 1 & 1 & 1 & 1 & 0 & 1 & 0 & 0 & 0 & 0 & 8 \\
S4 & 0 & 1 & 1 & 0 & 1 & 1 & 1 & 1 & 1 & 0 & 0 & 0 & 0 & 1 & 0 & 8 \\
S9 & 0 & 1 & 1 & 1 & 1 & 1 & 1 & 1 & 1 & 1 & 0 & 0 & 0 & 0 & 0 & 8 \\
S10 & 0 & 1 & 1 & 0 & 1 & 1 & 1 & 1 & 1 & 0 & 1 & 0 & 0 & 0 & 0 & 8 \\
S8 & 0 & 1 & 1 & 1 & 1 & 1 & 1 & 1 & 1 & 1 & 1 & 1 & 0 & 0 & 0 & 11 \\
S14 & 1 & 1 & 1 & 1 & 1 & 1 & 1 & 0 & 1 & 1 & 1 & 0 & 1 & 0 & 0 & 11 \\
S15 & 1 & 1 & 1 & 1 & 1 & 0 & 1 & 1 & 1 & 1 & 1 & 0 & 1 & 0 & 0 & 11 \\
S7 & 1 & 1 & 1 & 1 & 1 & 1 & 1 & 1 & 1 & 1 & 1 & 1 & 1 & 0 & 1 & 14 \\
Dependence power & 3 & 10 & 10 & 6 & 10 & 10 & 10 & 10 & 11 & 5 & 7 & 3 & 4 & 1 & 2 & \\
\hline
\end{tabular}

(ii) Success factors in dependent quadrant: this quadrant includes the success which has weak driving power but in the other side has strong dependence power and is represented in Section 2.

(iii) Success factors in linkage quadrant: in this section, the successes at the same time have strong driving power and strong dependence. They are represented in Section 3. These successes are unstable and any reaction on them will make an impression on the other successes.

(iv) Success factors in independent quadrant: in this section, the successes have enough strong driving power but very weak dependence power. These are placed in Section 4.

\section{Discussions of Findings}

Our study has implications for SSCM managerial practice, in terms of offering guidelines on those factors that managers should pay attention to in order to adopt SSCM practices in their organizations and supply chains. In particular, our study underlines the role of institutional pressures on internal pressures and commitment. Therefore, managers should be aware on how to "translate" these pressures into appropriate strategies and strategic collaboration with suppliers in order to achieve sustainability. The role of green product design as enabled by continuous improvement is important, and information needed for this purpose could be provided by appropriate information technologies. Logistics and warehousing should be also improved, and particular changes in these operations will enable organizations and supply chains to become more environmentally friendly and will also help them become economically viable and stable. Paying attention to these drivers means acquiring and cultivating particular employee skills; hence, this study proposes that managers should also attend to the different skills and capabilities needed to achieve SSCM, as determined by the proposed drivers. During the production, customer service, consumption, post-disposal disposition, and entire supply chain, the local optimization of environmental factors will be considered [60].

Although industrial development in Iran is acceptable, the consequences of this growth towards ecology should also be considered. Environmental issues are vital for industries, and for both managers and executive engineers, implementation of SSCM is challenging. However, the establishment of SSCM is not a simple job and it needs accurate analysis. The output of this research demonstrates that Iranian industrial top level managers have begun to arrange sustainability concerns in sustainable development and environmental science. But the point is not only that they are in the initial phase but also that they have to get rid of the barriers step by step.

The dependence and driving power demonstrate the 15 success positions in 4 sections (Figure 5). The outcome of this research of success analysis with the ISM approach is presented as the following clarification:

(i) In autonomous success factors, just one success factor S(9) appears in this section. Generally, autonomous successes are not strong drivers but are weak dependent and these success factors do not have much effect on the approach. This graph shows that nearly all successes play a significant role in the match on the SSCM in electrical power supply industries.

(ii) In dependent success factors area, there are two success factors $S(10)$ and $S(14)$. This section is mentioned as dependent quadrant, and the success in this section does not have strong driving power and also high dependence power. Considering the information quality and sharing in industries will drive power for these success factors [56] and also 
high dependence power is indicated as the absence of corporative social obligation as a significant barrier to the implementation of SSCM approach. These point out that those industries are giving minimum attention to social issue and governmental regulation. So, in our research case, we need the government to build proper framework to draw special attention to social responsibility for Iranian industries. Following these points, the Iranian industries are not specially motivated to social responsibility participation without outside pressure [61].

(iii) Six success factors, $\mathrm{S}(1), \mathrm{S}(2), \mathrm{S}(3), \mathrm{S}(8), \mathrm{S}(11)$, and $\mathrm{B}(15)$, fall in linkage success factors section. These success factors are organized into one group. Maintaining the environmental awareness of suppliers is the main issue in this quadrant. The success factors which are placed in this section have both strong driving and at the same time strong dependence power and they are unstable too. Any reaction on these successes will have an action on the other success and will also provide feedback. Also they might agitate all system specifications [58, 62].

(iv) $S(4), S(5), S(6), S(7), S(12)$, and $S(13)$ are given in dependent success factors in section. These success factors have a strong driving power but weak dependence power and this may be known as "key successes." Among these success factors S(12) "fearlessness of failure" and S(7) "economic benefits" are in top levels. The suppliers always are fighting to avoid recession in their workplace and practice to implement the appropriate sustainability model, because they are faced with high investments and low profit. Supply chain management contributes to the overall accomplishment of a supply chain, and one poor supplier activity affects very quickly the performance of the whole chain [61]. S(5), S(6), and $\mathrm{S}(13)$, "encouragement from customers," "motivation of suppliers and vendors towards green practices," and "pressure from non-government organizations (NGOs) lobby," are also in the same layers. Growing human skill in a company will supply goal attainment, being employee-oriented, and quality in productivity [59].

\section{Conclusion}

In the era of globalization, industries are facing pressure to greening their supply chain from intentional and domestic levels. It is because the environmental concerns have been gaining more attentions recently among organizations, and an adequately significant number of factors related to environmental and sustainable issues still need to be recognized from industrial viewpoints. In present work, we make an attempt to recognize the major critical success factors that facilitate successful implementation of SSCM practices towards sustainable development. At first, based on systematic review (Section 2) we focused on some high prestige scientific journals to investigate dominant success in
SSCM practices. In second stage, we applied ISM and MICMAC analysis to understand the relationships of 15 success factors in the implementation of sustainable supply chain management. It is impossible to reach all kinds of success; therefore, companies need to know the most obtained success factors based on their policy. This research summarizes the data analysis of success factors and categorizes success factors with ISM and MICMAC support.

In Figure 6, ISM diagram indicates the connection between the success factors. There are six levels in this diagram. One success factor drops in the first level, which is "information quality and sharing" (S10). This success factor is less influential for the implementation of sustainable supply chain management in electrical power supply industries. In the middle levels, the four success factors appeared. In the end, (S10) and (S15) that occur in the lower level play an influential role in adopting sustainable supply chain management. Industries need to give more attention to these success factors. The ISM outcome identifies the most significant success in electrical power supply industries which can easily help to process for the implementation of sustainable supply chain management.

Based on MICMAC analysis (Figure 5), one barrier (S6) has been reported as autonomous. The success factor "firm's competitiveness" has little link to the system, with low driving power and minimum dependency. It mentions that key variables are nominated as the success factor with a very strong driving power. They are independent or linkage criteria. We can call (S15) "problem in maintaining the environmental awareness of suppliers" the high impact key barrier, which also is dominated by (S1), (S2), (S3), (S8), and (S11), respectively.

In this study we have not used a structured questionnaire to further test the framework. Instead we relied completely on a survey of the perceptions of experts for developing the theoretical model, which alone may not be sufficient to statistically test the framework, and this is a limitation of the ISM method. For future research, a structured questionnaire could be prepared and a survey must be conducted by targeting highly experienced supply chain professionals, who embrace sustainability thinking in their operations to test the framework. We believe that our study provides useful thoughts for those who would like to further engage in theory building on the drivers of SSCM. In addition, Fuzzy ISM (FISM) $[63,64]$, which could be a progress over normal ISM, has been advised to expand ISM in fuzzy environment. It could specify the several network structures in the principles and practices.

\section{Conflicts of Interest}

The authors declare that they have no conflicts of interest.

\section{Authors' Contributions}

Professor Jianqiu Zeng made precious editorial contributions to improving the presentation of this paper. 


\section{Acknowledgments}

This work is supported by China National Key Research and Development Program under Grant no. 2016YFC0803206.

\section{References}

[1] Y. Y. Yusuf, A. Gunasekaran, A. Musa, M. Dauda, N. M. ElBerishy, and S. Cang, "A relational study of supply chain agility, competitiveness and business performance in the oil and gas industry," International Journal of Production Economics, vol. 147, pp. 531-543, 2014.

[2] H. Ding, Q. Zhao, Z. An, and O. Tang, "Collaborative mechanism of a sustainable supply chain with environmental constraints and carbon caps," International Journal of Production Economics, 2014.

[3] S. Luthra, K. Govindan, D. Kannan, S. K. Mangla, and C. P. Garg, "An integrated framework for sustainable supplier selection and evaluation in supply chains," Journal of Cleaner Production, vol. 140, pp. 1686-1698, 2017.

[4] Z. Wu and M. Pagell, "Balancing priorities: Decision-making in sustainable supply chain management," Journal of Operations Management, vol. 29, no. 6, pp. 577-590, 2011.

[5] W. Qian, "Environmental management accounting and supply chain management," Journal of Cleaner Production, vol. 20, no. 1, pp. 186-187, 2012.

[6] WBCSD, "World Business Council for Sustainable Development," in Sustainable Production Consumption from a Business Perspective. A status report by WBCSD, 2008.

[7] Carbon Disclosure Projec, Carbon Disclosure Project Supply Chain Report. Migrating to a Low Carbon Economy through Leadership and Collaboration, London, UK.

[8] F. Li, S. Dong, Z. Li, Y. Li, S. Li, and Y. Wan, "The improvement of $\mathrm{CO}_{2}$ emission reduction policies based on system dynamics method in traditional industrial region with large $\mathrm{CO}_{2}$ emission," Energy Policy, vol. 51, pp. 683-695, 2012.

[9] R. Mungkung, J. Aubin, T. H. Prihadi, J. Slembrouck, H. M. G. Van Der Werf, and M. Legendre, "Life cycle assessment for environmentally sustainable aquaculture management: a case study of combined aquaculture systems for carp and tilapia," Journal of Cleaner Production, vol. 57, pp. 249-256, 2013.

[10] C. S. Tang and S. Zhou, "Research advances in environmentally and socially sustainable operations," European Journal of Operational Research, vol. 223, no. 3, pp. 585-594, 2012.

[11] L. Luo, L. Qin, Y. Wang, and Q. Wang, "Environmentallyfriendly agricultural practices and their acceptance by smallholder farmers in China-a case study in Xinxiang County, Henan Province," Science of the Total Environment, vol. 571, pp. 737-743, 2016.

[12] B. Fahimnia, J. Sarkis, and H. Davarzani, "Green supply chain management: a review and bibliometric analysis," International Journal of Production Economics, vol. 162, pp. 101-114, 2015.

[13] GPS 2003-2016 Visualizer, http://www.gpsvisualizer.com/map_ input.

[14] J.-J. Huang, G.-H. Tzeng, and C.-S. Ong, "Multidimensional data in multidimensional scaling using the analytic network process," Pattern Recognition Letters, vol. 26, no. 6, pp. 755-767, 2005.

[15] Z. Wang, K. Mathiyazhagan, L. Xu, and A. Diabat, "A decision making trial and evaluation laboratory approach to analyze the barriers to green supply chain management adoption in a food packaging company," Journal of Cleaner Production, 2015.
[16] N. Subramanian and R. Ramanathan, "A review of applications of analytic hierarchy process in operations management," International Journal of Production Economics, vol. 138, no. 2, pp. 215-241, 2012.

[17] W. F. Lam, "Institutional design of public agencies and coproduction: a study of irrigation associations in Taiwan," World Development, vol. 24, no. 6, pp. 1039-1054, 1996.

[18] F. Knobloch and J.-F. Mercure, "The behavioural aspect of green technology investments: A general positive model in the context of heterogeneous agents," Environmental Innovation and Societal Transitions, vol. 21, pp. 39-55, 2016.

[19] P. Waide and C. Brunner, "Energy-efficiency policy opportunities for electric motor-driven systems. Energy efficiency series working paper," International Energy Agency, 2011.

[20] A. Kolk, "The social responsibility of international business: from ethics and the environment to CSR and sustainable development," Journal of World Business, 2015.

[21] V. Mani, R. Agarwal, A. Gunasekaran, T. Papadopoulos, R. Dubey, and S. J. Childe, "Social sustainability in the supply chain: construct development and measurement validation," Ecological Indicators, vol. 71, pp. 270-279, 2016.

[22] K. H. Brunk, "Exploring origins of ethical company/brand perceptions - a consumer perspective of corporate ethics," Journal of Business Research, vol. 63, no. 3, pp. 255-262, 2010.

[23] A. Sallez, "Sous-traitance, productivité économique et croissance régionale," Appliquée, vol. 2/3, pp. 459-496, 1975.

[24] J. Fisher, "Business marketing and the ethics of gift giving," Industrial Marketing Management, vol. 36, no. 1, pp. 99-108, 2007.

[25] J. A. Wade, "Chapter 6 - Stakeholders, ethics and social responsibility in the food supply chain," in Food Supply Chain Management, Chapter 6, pp. 111-124, Oxford, UK, 2001.

[26] R. Imrie and J. Morris, A review of recent changes in buyersupplier relations, 1992.

[27] W. J. Yoon and K. S. Park, "A study on the market instability index and risk warning levels in early warning system for economic crisis," Digital Signal Processing, vol. 29, pp. 35-44, 2014.

[28] R. Cerchione and E. Esposito, "A systematic review of supply chain knowledge management research: State of the art and research opportunities," International Journal of Production Economics, vol. 182, pp. 276-292, 2016.

[29] A. H. Tabassam, S. H. Hashmi, and F. U. Rehman, "Nexus between political instability and economic growth in pakistan," Procedia - Social and Behavioral Sciences, vol. 230, pp. 325-334, 2016.

[30] A. Alesina, S. Ozler, N. Roubini, and P. Swagel, "Political instability and economic growth," National Bureau of Economic Research, Cambridge, UK, 1992.

[31] M. Pasban and S. H. Nojedeh, "A review of the role of human capital in the organization," in Proceedings of the $3 \mathrm{rd}$ International Conference on New Challenges in Management and Organization, vol. 230, pp. 249-253, Organization and Leadership, 2016.

[32] J. H. Grimm, J. S. Hofstetter, and J. Sarkis, "Exploring subsuppliers' compliance with corporate sustainability standards," Journal of Cleaner Production, vol. 112, pp. 1971-1984, 2016.

[33] M. Wilhelm, C. Blome, E. Wieck, and C. Y. Xiao, "Implementing sustainability in multi-tier supply chains: strategies and contingencies in managing sub-suppliers," International Journal of Production Economics, vol. 182, pp. 196-212, 2016. 
[34] J. O. Okeniyi, O. A. Omotosho, O. O. Ogunlana et al., "Investigating prospects of phyllanthus muellerianus as ecofriendly/sustainable material for reducing concrete steelreinforcement corrosion in industrial/microbial environment," Energy Procedia, vol. 74, pp. 1274-1281, 2015.

[35] S. Kerdsuwan, K. Laohalidanond, and W. Jangsawang, "Sustainable development and eco-friendly waste disposal technology for the local community," Energy Procedia, vol. 79, pp. 119-124, 2015.

[36] M. Kishna, E. Niesten, S. Negro, and M. P. Hekkert, “The role of alliances in creating legitimacy of sustainable technologies: a study on the field of bio-plastics," Journal of Cleaner Production, vol. 155, pp. 7-16, 2017.

[37] S. Luthra, S. Kumar, D. Garg, and A. Haleem, "Barriers to renewable/sustainable energy technologies adoption: Indian perspective," Renewable \& Sustainable Energy Reviews, vol. 41, pp. 762-776, 2015.

[38] R. Dubey, A. Gunasekaran, T. Papadopoulos, S. J. Childe, K. Shibin, and S. F. Wamba, "Sustainable supply chain management: framework and further research directions," Journal of Cleaner Production, vol. 142, pp. 1119-1130, 2017.

[39] K. Govindan and H. Soleimani, "A review of reverse logistics and closed-loop supply chains: a journal of cleaner production focus," Journal of Cleaner Production, vol. 142, no. 1, pp. 371-384, 2017.

[40] Y. Wang, J. R. Huscroft, B. T. Hazen, and M. Zhang, "Green information, green certification and consumer perceptions of remanufctured automobile parts," Resources, Conservation \& Recycling, 2016.

[41] M. Levy and P. Powell, "Information systems strategy for small and medium sized enterprises: An organisational perspective," The Journal of Strategic Information Systems, vol. 9, no. 1, pp. 63$84,2000$.

[42] S. Dowlatshahi, "Developing a theory of reverse logistics," Interfaces, vol. 30, no. 3, pp. 143-155, 2000.

[43] Y. Zhang, L. Yin, and X. Li, "A decision study on river carrying capacity of changsha-zhu-tan region," Systems Engineering Procedia, vol. 1, pp. 422-431, 2011.

[44] H. Ding, Q. Liu, and L. Zheng, "Assessing the economic performance of an environmental sustainable supply chain in reducing environmental externalities," European Journal of Operational Research, vol. 255, no. 2, pp. 463-480, 2016.

[45] S. Gold, S. Seuring, and P. Beske, "Sustainable supply chain management and inter-organizational resources: a literature review," Corporate Social Responsibility and Environmental Management, vol. 17, no. 4, pp. 230-245, 2010.

[46] E. Chardine-Baumann and V. Botta-Genoulaz, "A framework for sustainable performance assessment of supply chain management practices," Computers \& Industrial Engineering, vol. 76, no. 1, pp. 138-147, 2014.

[47] F. Taillandier, L. Mora, and D. Breysse, "Decision support to choose renovation actions in order to reduce house energy consumption - An applied approach," Building and Environment, vol. 109, pp. 121-134, 2016.

[48] A. Diabat, D. Kannan, and K. Mathiyazhagan, "Analysis of enablers for implementation of sustainable supply chain management - a textile case," Journal of Cleaner Production, vol. 83, pp. 391-403, 2014.

[49] M. D. P. Pablo-Romero, R. Pozo-Barajas, and A. Sánchez-Braza, "Analyzing the effects of energy action plans on electricity consumption in covenant of mayors signatory municipalities in Andalusia," Energy Policy, vol. 99, pp. 12-26, 2016.

[50] P. Ahi and C. Searcy, "An analysis of metrics used to measure performance in green and sustainable supply chains," Journal of Cleaner Production, vol. 86, pp. 360-377, 2015.

[51] K. Mathiyazhagan, K. Govindan, A. NoorulHaq, and Y. Geng, "An ISM approach for the barrier analysis in implementing green supply chain management," Journal of Cleaner Production, vol. 47, pp. 283-297, 2013.

[52] J. N. Warfield, "Toward interpretation of complex structural models," IEEE Transactions on Systems, Man, and Cybernetics, vol. 4, no. 5, pp. 405-417, 1974.

[53] S. Luthra, D. Garg, and A. Haleem, "Critical success factors of green supply chain management for achieving sustainability in Indian automobile industry," Production Planning and Control, vol. 26, no. 5, pp. 339-362, 2015.

[54] J. N. Warfield, "Developing interconnection matrices in structural modeling," IEEE Transactions on Systems, Man, and Cybernetics, vol. SMC-4, no. 1, pp. 81-87, 1974.

[55] J. Hörisch, E. Ortas, S. Schaltegger, and I. Álvarez, "Environmental effects of sustainability management tools: an empirical analysis of large companies," Ecological Economics, vol. 120, pp. 241-249, 2015.

[56] V. Narayanaswamy and L. Stone, "From cleaner production to sustainable production and consumption in Australia and New Zealand: achievements, challenges, and opportunities," Journal of Cleaner Production, vol. 15, no. 8-9, pp. 711-715, 2007.

[57] S. Sindhu, V. Nehra, and S. Luthra, "Identification and analysis of barriers in implementation of solar energy in Indian rural sector using integrated ISM and fuzzy MICMAC approach," Renewable \& Sustainable Energy Reviews, vol. 62, pp. 70-88, 2016.

[58] E. A. Adegbola, “Corporate social responsibility as a marketing strategy for enhanced performance in the nigerian banking industry: a granger causality approach," Procedia - Social and Behavioral Sciences, vol. 164, pp. 141-149, 2014.

[59] A. Jayant and M. Azhar, "Analysis of the barriers for implementing green supply chain management (GSCM) practices: an interpretive structural modeling (ISM) approach," in Proceedings of the 12th Global Congress on Manufacturing and Management, GCMM 2014, pp. 2157-2166, India, December 2014.

[60] D. Kannan, R. Khodaverdi, L. Olfat, A. Jafarian, and A. Diabat, "Integrated fuzzy multi criteria decision making method and multi-objective programming approach for supplier selection and order allocation in a green supply chain," Journal of Cleaner Production, vol. 47, pp. 355-367, 2013.

[61] A. Ohuchi and I. Kaji, "Correction Procedures for Flexible Interpretive Structural Modeling," IEEE Transactions on Systems, Man, and Cybernetics, vol. 19, no. 1, pp. 85-94, 1989.

[62] P. Seri and A. Zanfei, "The co-evolution of ICT, skills and organization in public administrations: Evidence from new European country-level data," Structural Change and Economic Dynamics, vol. 27, pp. 160-176, 2013.

[63] T. Wakabayashi, L. Itoh, and A. Ohuchi, "A method for constructing system models by fuzzy flexible interpretive structural modeling," in Proceedings of the 1995 IEEE International Conference on Fuzzy Systems. The International Joint Conference of the Fourth IEEE International Conference on Fuzzy Systems and The Second International Fuzzy Engineering Symposium, pp. 913918, Yokohama, Japan, 1995. 
[64] A. Ohuchi, S. Kase, and I. Kaji, "MINDS: a flexible interpretive structural modeling system," in Proceedings of the 1988 IEEE International Conference on Systems, Man, and Cybernetics, pp. 1326-1329, Beijing, China. 


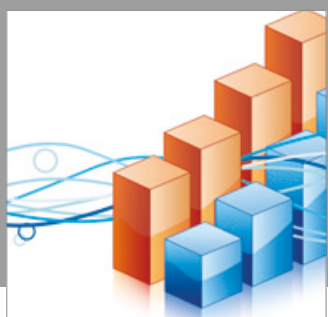

Advances in

Operations Research

vatersals

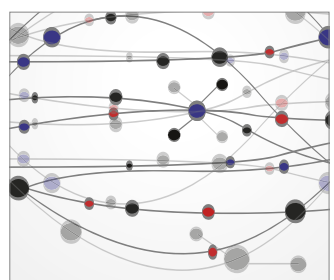

\section{The Scientific} World Journal
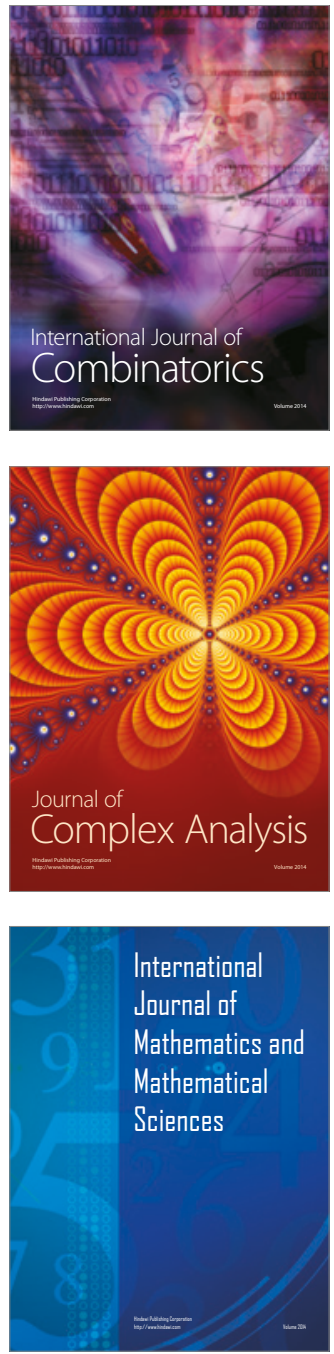
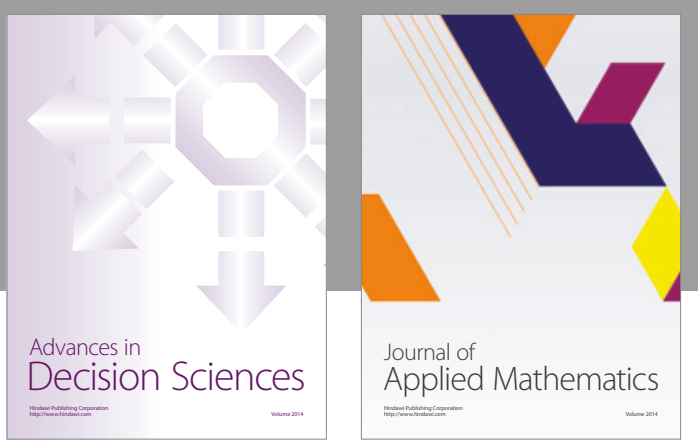

Algebra

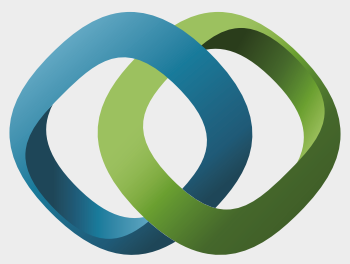

\section{Hindawi}

Submit your manuscripts at

https://www.hindawi.com
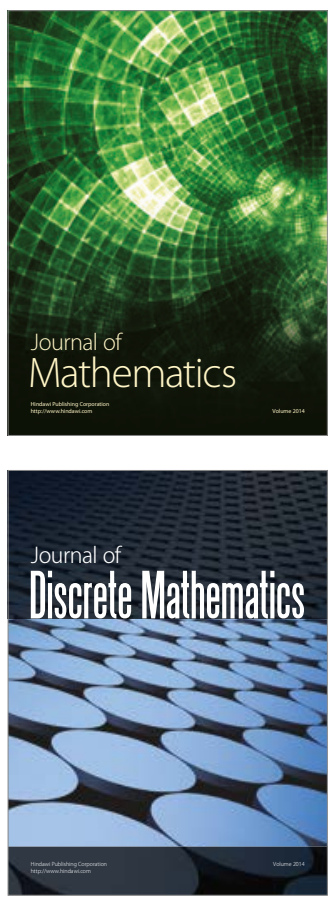

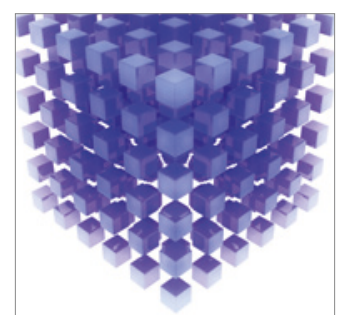

Mathematical Problems in Engineering
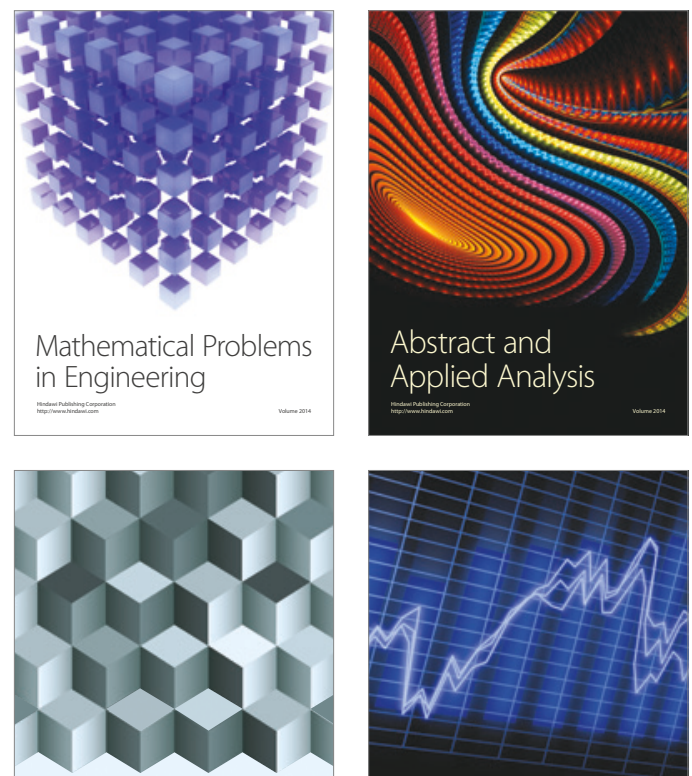

Journal of

Function Spaces

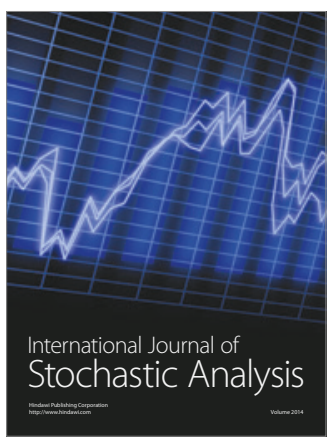

Probability and Statistics
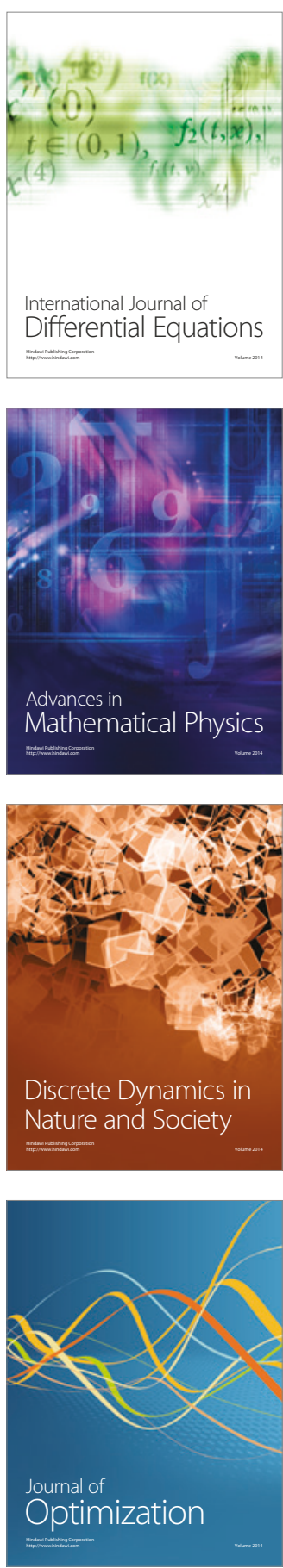